\title{
How hospitable is Aotearoa New Zealand to refugees?
}

\section{Alison McIntosh and Cheryl Cockburn-Wootten}

\author{
Professor Alison \\ McIntosh's research \\ focuses on issues of social \\ justice and advocacy \\ through tourism and \\ hospitality in the pursuit \\ of social change.
}

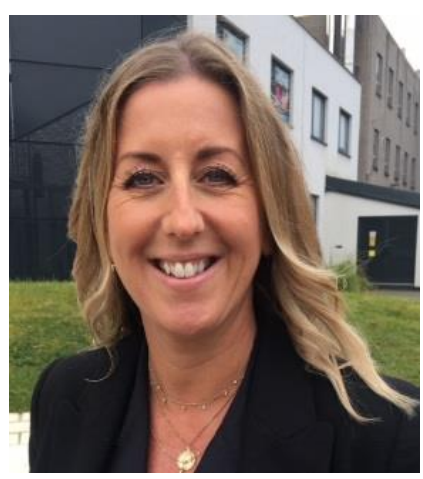

Dr Cheryl Cockburn-

Wootten is a flipped academic whose research focuses on applying critical communication and organisational communication perspectives to tourism and hospitality.

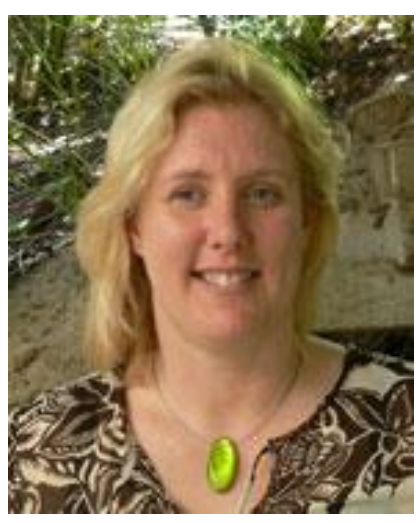

Following the tragic events of the Christchurch shooting on 15th March 2019, New Zealanders projected a national image of hospitality towards Muslim New Zealanders, involving an Islamic call to prayer in Parliament, and women wearing hijab in solidarity - unique public demonstrations of compassion and inclusion. In 2020, the New Zealand government will raise its refugee quota to 1,500 refugees per year as part of its United Nations obligations and remove its race-based aspects [1]. Globally, there are vast displacements of people fleeing persecution and economic oppression [2]. Arguably, despite its small refugee resettlement quota, New Zealand appears hospitable. Yet our study reveals a context within which negative economic, social and political factors dominate policy and practices. It similarly highlights ways in which New Zealand's hospitality towards refugees is paternalistic and interventionist, even if not deliberately [3].

'Being hospitable' is typically defined as a social relation that accompanies the ideologies and unconditional practices of 'welcome' [4]. As an act of welcome, hospitality gives ethical recognition to the stranger. This practice of hospitality enables and resonates a feeling of belonging and inclusion. However, the intrinsic nature of hospitality may foster exclusion as well as inclusion. The Christchurch incident arose from an act of unwelcome and a false sense of security from authorities as previous discrimination reported by the local refugee Muslim community was ignored. As such, key questions remain about how hospitable New Zealand is to refugees.

When refugees are resettled into a destination, refugee-focused service providers (including not-for-profits, community groups and NGOs) offer frontline services to ease refugees' experiences of trauma and marginalisation. They provide advocacy and welcome through reception processes, translation services and multicultural centres. We facilitated a national think tank attended by 34 refugee-focused service providers to examine how they practice a hospitable welcome through their advocacy and frontline services and how the welcome could be improved.

Participants identified the need for greater collaboration and communication between refugee-focused service providers to enhance trust, relationships, to enable former refugees to feel safe in voicing their concerns and access services, and to reduce the competition and duplication of service provision in the face of scarce funding. They also recognised the need to increase attention to the notion of welcome and advocacy by adopting practices from non- 
interventionist actions that draw on the notion of welcome as empathetic, warm and connecting, with minimum rules, and to centre refugee voices with their active participation in policy development, service delivery and social inclusion activities. Participants also advocated continued efforts by the media and wider community to reduce discrimination and negative social dialogue around refugees and to encourage their social inclusion. To achieve these outcomes, participants raised the need to address the important issues of underfunding and strategy underpinning the delivery of refugee-focused service provision.

Overall, our findings suggest that beneath the initial welcoming surface, an alternative perspective may be concealed that restricts us from providing a broader inclusive hospitality and welcome into Aotearoa New Zealand. To bridge this potential impasse, a more humanistic approach is potentially required, where refugees actively co-create the critical framing of hospitality $[5,6]$ to better support their resettlement.

The original research on which this article is based is available here https://doi.org/10.1080/02642069.2018.1472243

\section{Corresponding author}

Alison McIntosh can be contacted at: alison.mcintosh@aut.ac.nz

\section{References}

(1) Graham-McLay, C. Under Pressure, New Zealand Ends Policy Branded Racist. The New York Times, Oct 4, 2019. https://www.nytimes.com/2019/10/04/world/asia/jacindaardern-refugees-new-

zealand.html?fbclid=IwAR0IYwr7Fl31gtQ9qXS0XTTLXyNkTXSC9DBWot0Mf0UtQLp 9EXTBKTmqcBk (accessed Oct 20, 2019).

(2) Goldin, I.; Cameron, G.; Balarajan, M. Exceptional People: How Migration Shaped our World and will Define our Future; Princeton University Press: Princeton, NJ, 2012.

(3) McIntosh, A.; Cockburn-Wootten, C. Refugee-Focused Service Providers: Improving the Welcome in New Zealand. The Service Industries Journal 2018. https://doi.org/10.1080/02642069.2018.1472243.

(4). Lynch, P.; Germann Molz, J.; McIntosh, A.; Lugosi, P.; Lashley, C. Theorizing Hospitality. Hospitality \& Society 2011, 1 (1), 3-24. https://doi.org/10.1386/hosp.1.1.3 2

(5) Still, J. Derrida and Hospitality: Theory and Practice; Edinburgh University Press: Edinburgh, 2010.

(6) Brebner, L.; McIntosh, A.; Ewazi, S.; van Veen, M. Eds. Tastes of Home; Auckland University of Technology: Auckland, 2018. 